\title{
Volatility of organic aerosol and its components in the megacity of Paris
}

\author{
Andrea Paciga ${ }^{1,2}$, Eleni Karnezi ${ }^{1,2}$, Evangelia Kostenidou ${ }^{3}$, Lea Hildebrandt ${ }^{4}$, Magda Psichoudaki ${ }^{3,5}$, \\ Gabriella J. Engelhart ${ }^{2}$, Byong-Hyoek Lee ${ }^{2}$, Monica Crippa ${ }^{6,7}$, André S. H. Prévôt ${ }^{6}$, Urs Baltensperger $^{6}$, and \\ Spyros N. Pandis ${ }^{1,3,5}$ \\ ${ }^{1}$ Department of Chemical Engineering, Carnegie Mellon University, Pittsburgh, PA, USA \\ ${ }^{2}$ Center for Atmospheric Particle Studies, Carnegie Mellon University, Pittsburgh, PA, USA \\ ${ }^{3}$ Inst. of Chemical Engineering Sciences, FORTH/ICEHT, Patras, Greece \\ ${ }^{4}$ McKetta Department of Chemical Engineering, University of Texas, Austin, TX, USA \\ ${ }^{5}$ Department of Chemical Engineering, University of Patras, Patras, Greece \\ ${ }^{6}$ Laboratory of Atmospheric Chemistry, Paul Scherrer Institute, Villigen PSI, 5232, Switzerland \\ ${ }^{7}$ European Commission, Joint Research Centre, Institute for Environment and Sustainability, Air and Climate Unit, \\ Via Fermi, 2749, 21027 Ispra, Italy
}

Correspondence to: Spyros N. Pandis (spyros@chemeng.upatras.gr)

Received: 15 June 2015 - Published in Atmos. Chem. Phys. Discuss.: 20 August 2015

Revised: 21 January 2016 - Accepted: 31 January 2016 - Published: 23 February 2016

\begin{abstract}
Using a mass transfer model and the volatility basis set, we estimate the volatility distribution for the organic aerosol (OA) components during summer and winter in Paris, France as part of the collaborative project MEGAPOLI. The concentrations of the OA components as a function of temperature were measured combining data from a thermodenuder and an aerosol mass spectrometer (AMS) with Positive Matrix Factorization (PMF) analysis. The hydrocarbon-like organic aerosol (HOA) had similar volatility distributions for the summer and winter campaigns with half of the material in the saturation concentration bin of $10 \mu \mathrm{g} \mathrm{m}^{-3}$ and another $35-40 \%$ consisting of low and extremely low volatility organic compounds (LVOCs with effective saturation concentrations $C^{*}$ of $10^{-3}-0.1 \mu \mathrm{g} \mathrm{m}^{-3}$ and ELVOCs $C^{*}$ less or equal than $10^{-4} \mu \mathrm{g} \mathrm{m}^{-3}$, respectively). The winter cooking OA (COA) was more than an order of magnitude less volatile than the summer COA. The low-volatility oxygenated OA (LV-OOA) factor detected in the summer had the lowest volatility of all the derived factors and consisted almost exclusively of ELVOCs. The volatility for the semi-volatile oxygenated OA (SV-OOA) was significantly higher than that of the LV-OOA, containing both semi-volatile organic components (SVOCs with $C^{*}$ in the $1-100 \mu \mathrm{g} \mathrm{m}^{-3}$ range) and LVOCs. The oxygenated OA (OOA) factor in winter con-
\end{abstract}

sisted of SVOCs (45\%), LVOCs ( $25 \%$ ) and ELVOCs (30\%). The volatility of marine OA (MOA) was higher than that of the other factors containing around $60 \%$ SVOCs. The biomass burning OA (BBOA) factor contained components with a wide range of volatilities with significant contributions from both SVOCs (50\%) and LVOCs (30\%). Finally, combining the bulk average $\mathrm{O}: \mathrm{C}$ ratios and volatility distributions of the various factors, our results are placed into the two-dimensional volatility basis set (2D-VBS) framework. The OA factors cover a broad spectrum of volatilities with no direct link between the average volatility and average $\mathrm{O}: \mathrm{C}$ of the OA components.

\section{Introduction}

Atmospheric aerosols have adverse effects on human health (Caiazzo et al., 2013; Pope et al., 2009) and contribute to climate change (IPCC, 2013). Over 50\% of the submicron particulate mass is often comprised of organic compounds (Zhang et al., 2007). OA (organic aerosol) originates from many different natural and anthropogenic sources and processes. It can be emitted directly, e.g., from fossil fuels and biomass combustion (so-called primary organic aerosol, 
POA) or can be formed by atmospheric oxidation of volatile, intermediate volatility and semi-volatile organic compounds (secondary organic aerosol, SOA). Since the oxidation pathways of organic vapors are complex and the corresponding reactions lead to hundreds or even thousands of oxygenated products for each precursor, our understanding of OA formation mechanisms and the OA chemical and physical properties remains incomplete. Furthermore, a lack of information regarding the sources along with the physical and chemical properties, and lifetime of organic aerosol (OA) has made predictions of OA concentrations by chemical transport models uncertain.

The volatility of atmospheric OA is one of its most important physical properties. It determines the partitioning of these organic compounds between the gas and particulate phases, the OA concentration, and the atmospheric fate of the corresponding compounds. Measurement of the OA volatility distribution has been recognized as one of the major challenges in our efforts to quantify the rates of formation of secondary organic particulate matter (Donahue et al., 2012). Thermodenuders (TD) have been developed to measure the volatility of ambient aerosol (Burtscher et al., 2001; Wehner et al., 2002, 2004; Kalberer et al., 2004; An et al., 2007). Most TDs consist of two basic parts: a heated tube where the more volatile particle components evaporate, leaving less volatile species behind, and the denuder tube, usually containing activated carbon where the evaporated material is adsorbed thus avoiding potential recondensation when the sample is cooled to room temperature. The aerosol mass fraction remaining (MFR) at a given temperature, after passing through the TD, is the most common way of reporting the TD measurements. The MFR, though an indirect metric of volatility for a specific TD operation, also depends on the aerosol concentration, size, enthalpy of vaporization, potential resistances to mass transfer, etc. (Riipinen et al., 2010).

The two-dimensional volatility basis set (2D-VBS) framework from Donahue et al. (2012) has been used in order to describe atmospheric OA formation and evolution by lumping all organic compounds (with the exception of VOCs) into surrogates along two axes of volatility and the oxygen content (expressed as the $\mathrm{O}: \mathrm{C}$ ratio or carbon oxidation state). Using the 2D-VBS requires the ability to measure the OA distribution as a function of volatility and $\mathrm{O}: \mathrm{C}$ ratio (or carbon oxidation state).

Positive Matrix Factorization (PMF), aims to deconvolve the bulk OA mass spectra obtained by the aerosol mass spectrometer (AMS) into individual "factors" that give information about the sources or processing of organic aerosol (Lanz et al., 2007; Ulbrich et al., 2009; Huffman et al., 2009; Zhang et al., 2011). Typical factors correspond to either primary sources including HOA (hydrocarbon-like OA), BBOA (biomass burning OA) and COA (cooking OA) or secondary OA like SV-OOA (semi-volatile oxygenated OA) and LVOOA (low volatility oxygenated OA). Although there have been numerous studies that have identified PMF factors in ambient data sets, there have been few studies that have attempted to estimate the corresponding factor volatility (Huffman et al., 2009; Cappa and Jimenez, 2010). Huffman et al. (2009) characterized the volatility of PMF factors derived for the MILAGRO campaign in Mexico City and for the SOAR-1 campaign in Riverside, CA. They concluded that BBOA was the most volatile and OOA was the least volatile component. HOA was more volatile than OOA in almost all cases. Cappa and Jimenez (2010), using a kinetic evaporation model, estimated the volatility distributions for the various PMF OA factors for the MILAGRO campaign. Here we extend this work focusing on another megacity, Paris.

In this study, we estimate the volatility distributions of PMF factors derived from two month-long summer and winter campaigns in a suburban background site in Paris. The data analysis approach is first outlined and the corresponding challenges are discussed. We use the mass transfer model of Riipinen et al. (2010), together with the approach introduced by Karnezi et al. (2014) to estimate the volatility distributions for all PMF factors. We finally synthesize the corresponding OA findings using the 2D-VBS framework.

\section{Methods}

\subsection{Measurement site and sampling}

Two comprehensive field campaigns were performed during July of 2009 and January/February of 2010 at an urban background sampling site, SIRTA (Site Instrumental de Recherche par Teledetection Atmospherique) (Haeffelin et al., 2005) located about $20 \mathrm{~km}$ southwest of Paris' city center. The data sets were collected as part of a collaborative project known as MEGAPOLI (Megacities: Emissions, urban, regional, and Global Atmospheric POLution and climate effects, and Integrated tools for assessment and mitigation) (Baklanov et al., 2008; Beekmann et al., 2015). A suite of instruments were used including a high-resolution time-offlight aerosol mass spectrometer (HR-ToF-AMS) from Aerodyne research, Inc. (DeCarlo et al., 2006) for particle mass and composition, a scanning mobility particle sizer (SMPS) from TSI, Inc. for particle size and number distributions and the Carnegie Mellon University thermodenuder (TD) for volatility measurements.

The TD design was similar to that described in An et al. (2007), consisting of a heated tube followed by a denuding section, which uses activated charcoal to prevent recondensation of organic vapors. The TD was operated at temperatures ranging from about 20 to $200^{\circ} \mathrm{C}$ during both campaigns, yielding thermograms of the organic aerosol mass remaining as a function of TD temperature. The TD scanned this temperature range using different temperatures each day. A centerline residence time of $25 \mathrm{~s}$ at $298 \mathrm{~K}$ was used for all measurements (Lee et al., 2010). This corresponds to a mean residence time of approximately $50 \mathrm{~s}$ at $298 \mathrm{~K}$. 


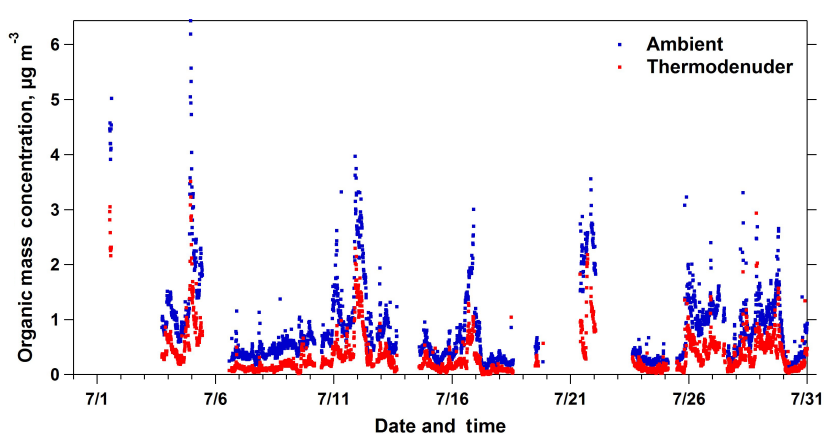

Figure 1. Ambient (blue dots) and thermodenuder (red dots) organic mass concentration measurements for Paris during summer 2009.

Changes in composition, mass, and size as a result of aerosol evaporation were quantified by both the SMPS and the HR-ToF-AMS by alternate sampling between the TD and the ambient sample line, every $5 \mathrm{~min}$. The SMPS was operated with a sheath flow of $5 \mathrm{~L} \mathrm{~min}^{-1}$ and a sample flow rate of $0.5 \mathrm{~L} \mathrm{~min}^{-1}$. The HR-ToF-AMS, which measures the aerosol size-composition distribution of the submicron nonrefractory material, was operated in both the higher sensitivity mode (V-mode) and the higher resolution mode (Wmode) (DeCarlo et al., 2006). The V-mode data are used in this study. The AMS collection efficiency was estimated at 0.38 during the summer (Crippa et al., 2013a) and 0.5 during the winter (Crippa et al., 2013b).

\subsection{Data analysis}

TD raw measurements need to be corrected for particle losses due to diffusion of small particles, sedimentation of larger particles, and thermophoretic losses (Burtscher et al., 2001). To account for these losses, which depend on particle size, TD temperature, and sample flow rate, Lee et al. (2010) have developed size and temperature-dependent corrections for this particular TD. The organic aerosol concentrations measured after the TD were corrected for losses corresponding to the operating conditions during the campaign. The OA mass fraction remaining (MFR) was calculated dividing the losscorrected OA concentration after the TD at time period $i$ with that of the by-pass line at time period $i+1$. The fact that the two measurements correspond to two different 5 min time intervals introduces some uncertainty in the calculated MFR values because of the variability of the atmospheric concentrations. Some of this variability is averaged out when average MFR values are calculated for each temperature.

The preparation of these large data sets for analysis required careful examination of the ambient OA variability in order to determine the appropriate averaging intervals. The OA mass concentration data for the summer campaign are shown in Fig. 1. Overall, the particulate matter mass concentration was surprisingly low during this period in Paris, with

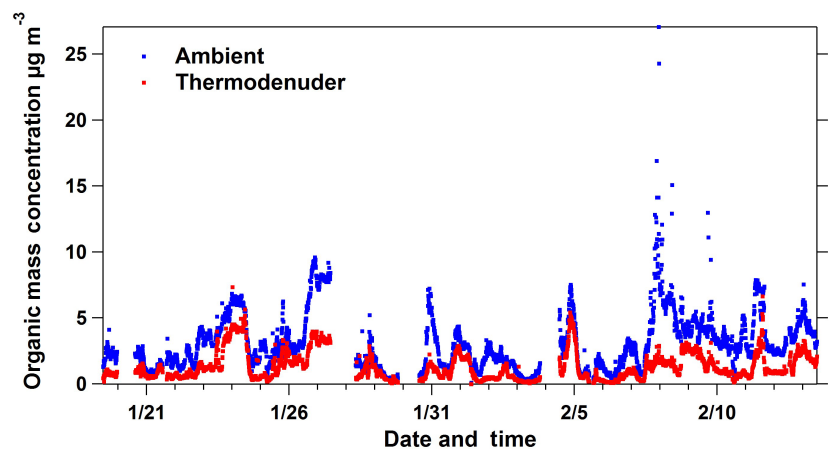

Figure 2. Ambient (blue dots) and thermodenuder (red dots) OA mass concentration time series for the winter 2010 campaign.

a campaign average $\mathrm{PM}_{1}$ OA for SIRTA of only $0.83 \mu \mathrm{g} \mathrm{m}^{-3}$. As expected, there were several periods during which the OA concentration was much higher than $1 \mu \mathrm{g} \mathrm{m}^{-3}$ reaching levels up to $6 \mu \mathrm{g} \mathrm{m}^{-3}$. To evaluate whether the OA during these higher concentration periods had different MFR values than the rest of the samples, we separated the data in two groups using an OA concentration cutoff of $1.5 \mu \mathrm{g} \mathrm{m}^{-3}$. Figure S1 in the Supplement shows the corresponding MFR measurements for both low and high concentration periods. Given the experimental variability, there is no discernable difference in evaporation between the higher and the lower concentration periods and, therefore, these were averaged together for the analysis. The similarity of the average MFR values during these low and high concentration periods (the latter were often characterized by higher OA variability) also suggests that our calculation of the MFR using measurement pairs did not introduce significant bias in the average estimated MFR.

We performed a similar analysis for the winter campaign. Paris during winter, unlike the summer, was characterized by higher fine $\mathrm{PM}$ concentrations with an average $\mathrm{PM}_{1} \mathrm{OA}$ concentration of $3.1 \mu^{-3} \mathrm{~m}^{-3}$ (Fig. 2). The OA threshold concentration was chosen to be $4.5 \mu \mathrm{g} \mathrm{m}^{-3}$ and again there was no evidence of effects of concentration (in the observed range) on volatility (Supplement, Fig. S2) and the corresponding MFRs were averaged together. Finally, the data points were averaged into temperature bins of $5^{\circ} \mathrm{C}$. The calculation of one MFR value every $5^{\circ} \mathrm{C}$ is a compromise between the need to average more data points at similar temperatures and maintaining the dynamic behavior of the thermogram. Averaging over wider temperature ranges (e.g. $10^{\circ} \mathrm{C}$ ) did not result in any essential differences in our analysis and conclusions.

Along with the bulk organic measurements, additional information can be derived from the HR-ToF-AMS V-mode mass spectra using the PMF analysis technique. The deconvolved spectra yielded several organic aerosol "factors" for each campaign. A complete discussion of the PMF analysis of the ambient measurements and the resulting factors can be found in Crippa et al. (2013a, b). The PMF analysis was repeated, combining both ambient and thermodenuded spectra 
with guidance from the original analysis of the ambient-only data (e.g., the same number of factors was used). This second analysis produced for all practical purposes the same results for the ambient data set as that of the ambient measurements only and can be found in the corresponding publications.

The low OA concentrations especially during the summer resulted in very low concentrations of the corresponding factors and thus high MFR uncertainty. The MFRs of the various factors were, as expected, extremely variable when the factor concentrations were close to zero. Therefore, to minimize these problems, a minimum ambient mass concentration was determined for each PMF factor, based on the concentration range for which MFR measurements exceeded 1.5. The average ambient concentration and threshold concentration with corresponding statistical information for each PMF factor is shown in Table 1. The corresponding factor concentration thresholds during the summer were in the $0.05-0.1 \mu \mathrm{g} \mathrm{m}^{-3}$ range. MFR measurements of PMF factors with ambient levels less than $0.1 \mu \mathrm{g} \mathrm{m}^{-3}$ are clearly quite uncertain. All the corresponding MFR values from these low factor concentration periods were excluded from the analysis. Few MFR measurements were excluded during the winter period, while $20-50 \%$ of the measurements for the various factors were excluded during the summer.

\subsection{Volatility distribution estimation}

To estimate the volatility distributions from the corrected thermograms we employed the dynamic mass transfer model of Riipinen et al. (2010). The model simulates particle evaporation using experimental inputs including TD temperature and residence time, initial particle size, and ambient OA concentration. The volatility of these complex mixtures is defined using the corresponding effective saturation concentration, $C^{*}$, at $298 \mathrm{~K}$. Along with saturation concentration, two parameters that can affect the evaporation rate and the corresponding volatility estimation are the enthalpy of vaporization and the mass accommodation coefficient. Unfortunately, these values are currently unknown for these complex multicomponent systems. Often, a mass accommodation coefficient of unity is assumed. However, mass transfer limitations to evaporation have been observed in some experimental systems, leading to mass accommodation coefficient values of much less than one (Saleh et al., 2013). Typical values of $100 \mathrm{~kJ} \mathrm{~mol}^{-1}$ and 1.0 are assumed for the enthalpy of vaporization and accommodation coefficient, respectively. Use of lower accommodation coefficient values results in shifting of the estimated volatility distributions to higher values. Lee et al. (2010) explored this sensitivity and estimated that an order of magnitude change in the mass accommodation coefficient was "equivalent" to a corresponding change in the volatility distribution. Similar conclusions about the sensitivity of the estimated volatility to the accommodation coefficient were reached by Cappa and Jimenez (2010) as well as Riipinen et al. (2010).

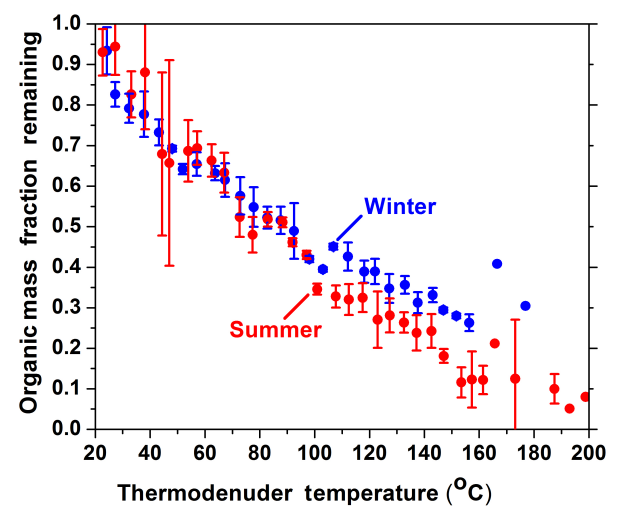

Figure 3. Loss-corrected average OA thermograms for summer (red circles) and winter (blue squares) campaigns. The error bars correspond to \pm 2 standard deviations of the mean. Points with no error bars correspond to a single measurement.

As described in Donahue et al. (2006), the volatility distribution is represented by surrogate species with a saturation concentration of $C_{i}^{*}$. The $C_{i}^{*}$ bins are logarithmically spaced, allowing for extremely low and high volatility species to be compared in a single framework. The analysis here was limited to a 6-consecutive $C^{*}$ bin solution with a variable mass fraction value for each bin. Different volatility ranges were tested and the best range was selected for each factor. The "goodness of fit" was quantified using the error analysis outlined in Karnezi et al. (2014). The standard error was calculated for all $C^{*}$ bin-mass fraction combinations. For a given 6-bin solution, the top $2 \%$ of mass fraction combinations with the lowest error was used to find the average mass fraction in each bin and the corresponding standard deviation.

The OA components are described as semi-volatile (SVOCs with $C^{*}$ of 1,10 , and $100 \mu \mathrm{g} \mathrm{m}^{-3}$ ), low volatility (LVOCs with $C^{*}$ of $10^{-3}, 10^{-2}$, and $0.1 \mu \mathrm{g} \mathrm{m}^{-3}$ ), and extremely low volatility (ELVOCs with $C^{*} \leq 10^{-4} \mu \mathrm{g} \mathrm{m}^{-3}$ ) in the rest of the paper (Murphy et al., 2014).

\section{Results and discussion}

\subsection{Organic aerosol volatility}

The average loss-corrected OA thermograms for the two seasons are shown in Fig. 3. The two thermograms seem very similar while differences are mostly noticeable at the high temperatures. In the winter thermogram an approximate $30 \%$ of the $\mathrm{OA}$ remained at $180^{\circ} \mathrm{C}$ while in the summer thermogram less than $10 \%$ was present at the same temperature. This might suggest more ELVOCs being present at winter. However, the summer thermogram shows that nearly $50 \%$ of the mass evaporated at a thermodenuder temperature of $83^{\circ} \mathrm{C}\left(T_{50}\right)$. The winter measurements suggested a similar $T_{50}$ value of $88^{\circ} \mathrm{C}$. This crude comparison of volatility through the corresponding thermograms suggests that the 
Table 1. Average and threshold ambient concentrations for each PMF factor.

\begin{tabular}{lcrrr}
\hline $\begin{array}{l}\text { PMF } \\
\text { Factor }\end{array}$ & Season & $\begin{array}{r}\text { Average mass } \\
\text { concentration } \\
\left(\mu \mathrm{g} \mathrm{m}^{-3}\right)\end{array}$ & $\begin{array}{r}\text { Threshold } \\
\text { concentration } \\
\left(\mu \mathrm{g} \mathrm{m}^{-3}\right)\end{array}$ & $\begin{array}{r}\text { Percentage of } \\
\text { measurements above } \\
\text { threshold }\end{array}$ \\
\hline HOA & Summer & 0.16 & 0.08 & 53 \\
COA & & 0.25 & 0.05 & 69 \\
MOA & & 0.17 & 0.10 & 73 \\
SV-OOA & & 0.65 & 0.10 & 82 \\
LV-OOA & & 0.12 & 0.08 & 69 \\
\hline HOA & Winter & 0.95 & 0.20 & 95 \\
COA & & 0.48 & 0.08 & 92 \\
BBOA & & 0.60 & 0.07 & 90 \\
OOA & 3.78 & 0.40 & 99 \\
\hline
\end{tabular}
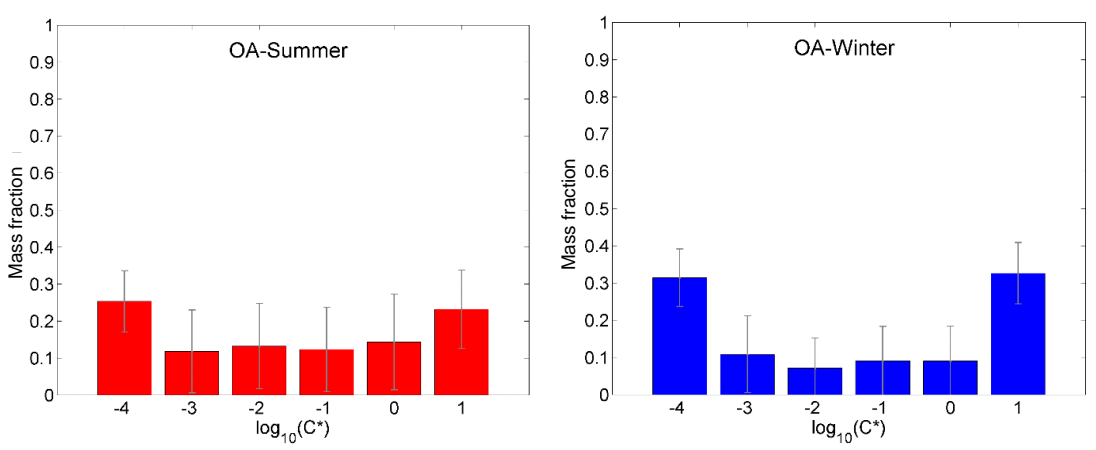

Figure 4. Estimated volatility distributions for summer (left panel) and winter total OA (right panel). The error bars correspond to the fitting uncertainties according to the algorithm of Karnezi et al. (2014).

OA in the two seasons could have similar average volatility distributions. It is surprising that the seasonal differences in emissions are not reflected in the corresponding thermograms. We will examine the reasons for this similarity in the subsequent section by analyzing the volatility of the corresponding factors.

The volatility distributions for the total OA for the two seasons are depicted in Fig. 4. They are quite similar to each other especially considering the corresponding uncertainties and they are characterized by higher concentrations of components with $C^{*}=10^{-4}$ and $10 \mu \mathrm{g} \mathrm{m}^{-3}$.

\subsection{Volatility of organic aerosol components}

Five PMF factors were determined for the summer data set by Crippa et al. (2013a). Hydrocarbon-like OA (HOA) most closely resembles fresh vehicle emissions in that the mass spectrum resembles that of transportation sources. Cooking OA (COA) was also observed in the summer campaign, peaking during noon and evening meal times. Marine OA (MOA) was identified based on relatively high levels of organic sulfur and a strong correlation with methanesulfonic acid (MSA), which is a product of continued oxidation of phytoplankton decomposition products. Two SOA factors were also reported: semi-volatile oxygenated OA (SV-OOA) and low-volatility oxygenated OA (LV-OOA). These two factors were differentiated based on their $\mathrm{O}: \mathrm{C}$ ratio. The two secondary OA factors made up $57 \%$ of the total OA mass. The remaining factors contributed fairly similar average fractions of $18 \%$ for COA, $12 \%$ for HOA, and $13 \%$ for MOA. Detailed discussion of the PMF factors along with verification analysis were provided by Crippa et al. (2013a).

The PMF analysis for the winter campaign yielded four factors. The HOA and COA factors were again present. There was also a single secondary OA factor which was termed oxygenated OA (OOA). This factor could not be further separated into SV-OOA and LV-OOA. The final factor reported was biomass burning OA (BBOA), correlating with known molecular markers for residential wood burning (e.g., levoglucosan). The OOA factor was found to dominate the organic aerosol mass, contributing nearly $65 \%$ on average. The complete analysis and description of these factors can be found in Crippa et al. (2013b).

Using the mass transfer model from Riipinen et al. (2010) and the approach of Karnezi et al. (2014) we fitted the corresponding thermograms (Fig. S3), using a $C^{*}$ bin solution with a variable mass fraction value for each bin. Specifically for each factor we used an individual consecutive 6-bin so- 

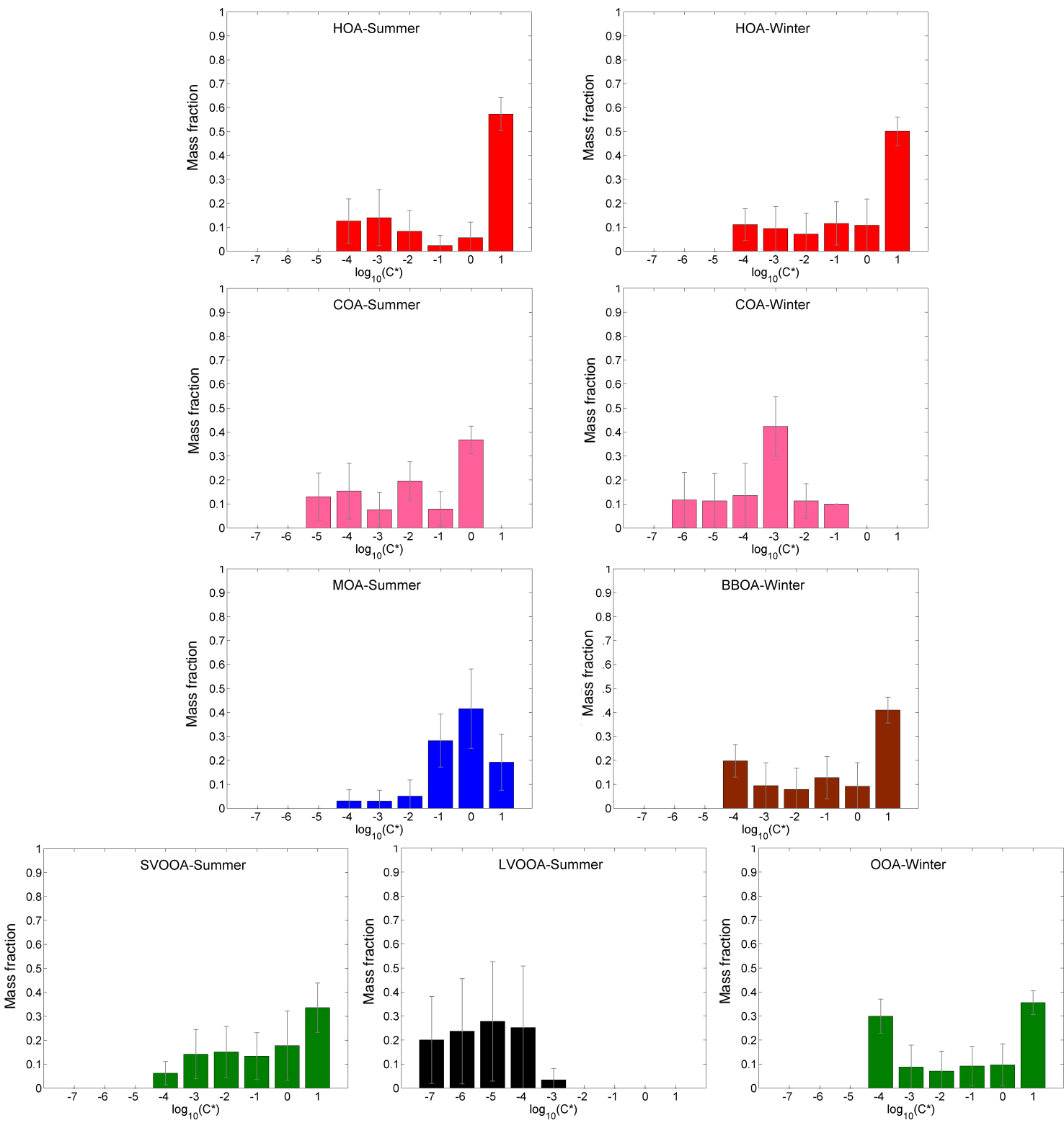

Figure 5. Estimated volatility distributions for summer PMF factors (left panel) and winter PMF factors (right panel). The error bars correspond to the fitting uncertainties according to the algorithm of Karnezi et al. (2014).

lution (chosen as the 6-bin solution with the best fits) resulting in the volatility distributions, shown in Fig. 5. The modeled thermograms for all factors from both summer and winter campaigns are shown in Fig. 6. Finally, the volatility distributions for each factor are summarized in Table S1 in the supplementary information. The fitting of individual factor thermograms implicitly assumes that each factor had the same size distribution as the total OA and that the factors were present as an external mixture. To test the uncertainty introduced by this assumption we compared the volatility distribution of the total OA with the composition weighted sum of the volatility distributions of the individual OA fac- tors for both summer and winter. The two distributions (total and sum of factors) agreed within a few percent for both seasons suggesting that the uncertainty is modest and within the uncertainty limits shown in the corresponding figures.

The HOA factors for the summer and winter campaigns had very similar thermograms and volatility distributions with half of the material in the $10 \mu \mathrm{g} \mathrm{m}^{-3}$ bin (Fig. 5). Roughly $40 \%$ of the HOA in both seasons consisted of LVOCs and ELVOCs. This volatility similarity is consistent with the similarity in mass spectra derived by the PMF analysis (Fig. 7a). The angle $\theta$ between the corresponding vectors (treating the AMS spectra as vectors according to 


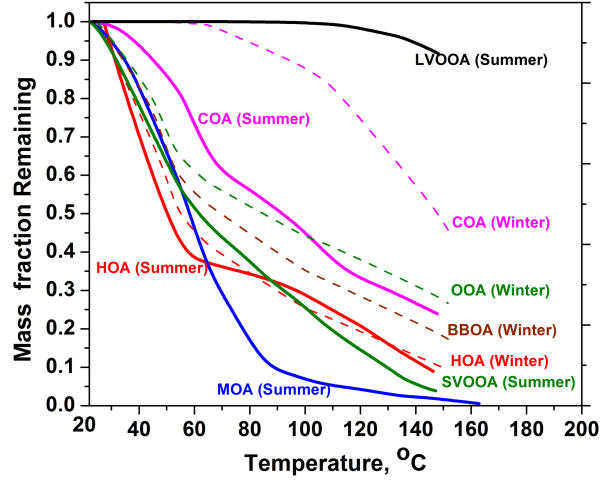

Figure 6. Estimated best-fit thermograms for all PMF factors. The solid lines represent the thermograms for the summer campaign and the dashed lines the thermograms for the winter campaign.

Kostenidou et al., 2009) was $14^{\circ}$ suggesting similar chemical fingerprints. This is not surprising for a megacity where the transportation and any industrial sources are expected to have chemically similar emissions in both summer and winter. Similar were also the $T_{50}$ for the HOA factors with values of 49 and $54{ }^{\circ} \mathrm{C}$ for the summer and winter campaign, respectively. Cappa and Jimenez (2010) also estimated that the HOA in Mexico City had a wide volatility distribution with approximately $35 \%$ of its mass consisting of LVOCs and ELVOCs while the remaining $65 \%$ was SVOCs. Almost $40 \%$ of the HOA had $C^{*} \geq 10 \mu \mathrm{g} \mathrm{m}^{-3}$ which compares very well with the $50 \%$ estimated here.

The situation was quite different for the cooking OA factor. Here the seasonal differences were more pronounced for the thermograms (Fig. 6), the estimated volatility distributions (Fig. 5) and the corresponding mass spectra (Fig. 7b). The winter COA was substantially less volatile than the summer COA, more than an order of magnitude based on average $\log C^{*}$ values, weighted by the mass fraction of each bin (average $C^{*}=10^{-2} \mu \mathrm{g} \mathrm{m}^{-3}$ for the summer campaign and average $C^{*}=4 \times 10^{-4} \mathrm{\mu g} \mathrm{m}^{-3}$ for the winter campaign). The COA factor during the winter campaign did not contain semivolatile components while $37 \%$ of the summer COA was semi-volatile. The COA winter factor consisted of ELVOCs (37\%) and LVOCs (63\%). The COA mass spectra in Fig. 7b show that the winter COA was characterized by a higher fraction of molecular fragments at higher mass-to-charge $(\mathrm{m} / \mathrm{z})$ ratio. This is consistent with organic components of longer carbon chain which, for the same level of oxidation, are expected to have lower volatility. The angle $\theta$ between the COA spectra was $26^{\circ}$, suggesting a significant chemical difference. One explanation is that the cooking habits are different in the two seasons with outdoor cooking (e.g., barbecue) dominating in the summer and indoor cooking relying more on oil and butter, being more significant in the winter. We also cannot rule out some imperfect unmixing of OA sources and components. The $T_{50}$ for the COA factors were different as
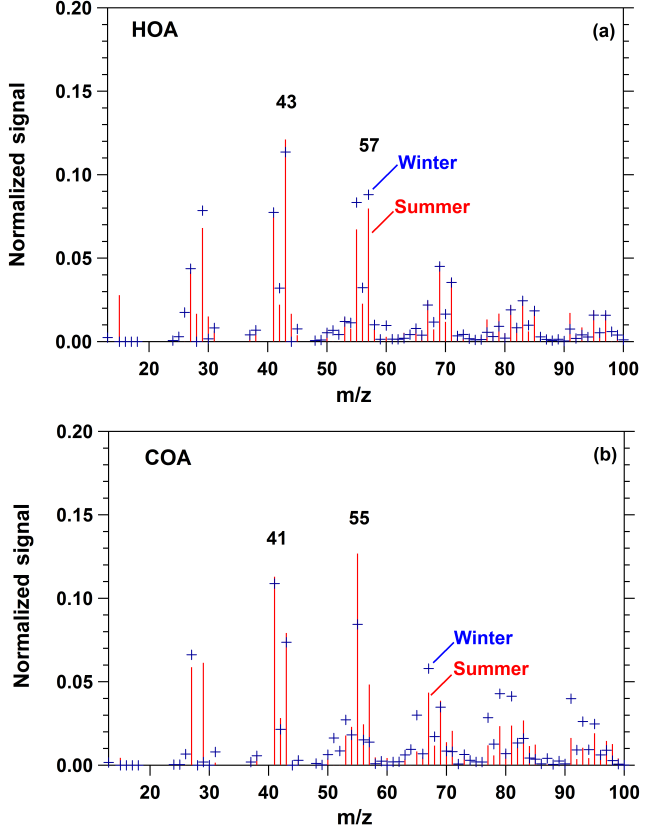

Figure 7. Seasonal mass spectra comparison for (a) HOA and (b) COA in Paris. Red lines correspond to the summer measurements while blue symbols correspond to the winter data.

well, with values of 91 and $148^{\circ} \mathrm{C}$ for the summer and winter campaign, respectively.

The LV-OOA factor detected in the summer had the lowest volatility (Fig. 5) of all the derived factors. There was no sign of evaporation until the TD temperature reached nearly $150^{\circ} \mathrm{C}$ (Fig. 6). We estimate that this factor consisted almost exclusively of OA with effective saturation concentrations equal to or lower than $10^{-3} \mu \mathrm{g} \mathrm{m}^{-3}$, which are almost exclusively ELVOCs. The average ambient concentration of this factor during the summer was $0.12 \mu \mathrm{g} \mathrm{m}^{-3}$ and its average $C^{*}$ was equal to $5 \times 10^{-6} \mu \mathrm{g} \mathrm{m}^{-3}$. Very low volatilities (practically all the OA had $C^{*} \leq 10^{-3} \mu \mathrm{g} \mathrm{m}^{-3}$ ) were also estimated for LV-OOA by Cappa and Jimenez (2010) in Mexico City during the MILAGRO campaign.

The estimated volatility for the SV-OOA factor is consistent with its naming by Crippa et al. (2013a) as it was significantly higher than that of the LV-OOA (Fig. 5). We estimated that roughly half of the SV-OOA was SVOCs while it contained also LVOCs $(42 \%)$ and a small amount of ELVOCs $(6 \%)$. Its $T_{50}$ was $61^{\circ} \mathrm{C}$ and its average $C^{*}$ was roughly $0.2 \mu \mathrm{g} \mathrm{m}^{-3}$. These values are once more generally consistent with the estimates of Cappa and Jimenez (2010) showing that SVOCs dominated the SV-OOA during MILAGRO (approximately $40 \%$ ) with LVOCs contributing another $35 \%$.

The OOA factor determined in the winter had a volatility distribution (Fig. 5), containing SVOCs (45\%), LVOCs $(25 \%)$ and ELVOCs (30\%). The winter OOA and the summer SV-OOA spectra had a $\theta$ angle of $34^{\circ}$, while there was an even larger discrepancy between the winter OOA and the 
summer LV-OOA with an angle of $37^{\circ}$. The $T_{50}$ was equal to $85^{\circ} \mathrm{C}$. These differences in mass spectra and $T_{50}$ are consistent with the differences in volatility. The average volatility of OOA was much higher than LVOOA in summer but lower than SVOOA.

The marine OA (MOA) factor was only detected during the summer campaign at an average concentration of $0.17 \mu \mathrm{g} \mathrm{m}^{-3}$. Its volatility was relatively high (Fig. 6), and almost all the MOA had evaporated at $100^{\circ} \mathrm{C}$. The MOA factor consisted mainly of SVOCs (61 \%) and some LVOCs (36\%). Its $T_{50}$ was equal to $58{ }^{\circ} \mathrm{C}$ and its average $C^{*}$ was approximately $0.4 \mu \mathrm{g} \mathrm{m}^{-3}$.

The BBOA factor was present in the winter data set with an average ambient concentration of $0.6 \mu \mathrm{g} \mathrm{m}^{-3}$. The corresponding estimated volatility distribution (Fig. 5) shows that half of the BBOA factor consisted of SVOCs (with most material in the $10 \mu \mathrm{g} \mathrm{m}^{-3} \mathrm{bin}$ ) and the other half of LVOCs and ELVOCs. A similar bimodal distribution was also found by May et al. (2013) with a peak at 0.01 and one at $100 \mu \mathrm{g} \mathrm{m}^{-3}$ for controlled biomass burning in the laboratory. The difference in the location of the high-volatility peak can potentially be explained by the wider range of concentrations in the experiments analyzed by May et al. (2013) compared to the limited range in the ambient Paris measurements. The more volatile BBOA components were never in the particulate phase in our data set so their abundance cannot be determined. The BBOA $T_{50}$ was $70^{\circ} \mathrm{C}$, higher than that of $\mathrm{HOA}$ and less than those of COA and OOA. Finally, its average $C^{*}$ was approximately $0.1 \mu \mathrm{g} \mathrm{m}^{-3}$. The BBOA in Mexico City was approximately half LVOCs and half SVOCs (Cappa and Jimenez, 2010) and had a much lower ELVOC fraction than the wintertime Paris BBOA in the present study.

\section{Synthesis of results in the 2D-VBS}

We employed the 2D-VBS framework in order to synthesize the above results, combining the bulk average $\mathrm{O}: \mathrm{C}$ ratio and volatility distributions of the various factors. Each of the different factors had a distribution of $\mathrm{O}: \mathrm{C}$ values, but this distribution cannot be determined from the AMS measurements. The HOA, BBOA, and COA factors all had relatively low $\mathrm{O}: \mathrm{C}$ values but they covered a wide range of average volatilities (Fig. 8). The MOA and secondary OA factors for both seasons had much higher $\mathrm{O}: \mathrm{C}$ values but they also covered a wide range of volatilities, with LV-OOA having the lowest one. The HOA during summer had higher $\mathrm{O}: \mathrm{C}$ than HOA during winter, suggesting incomplete separation from aged HOA or difference in the sources, while their volatility distribution was similar, as discussed earlier. The COA factor during the summer campaign had slightly higher $\mathrm{O}: \mathrm{C}$ and a higher volatility than the COA from the winter campaign. The OOA during the winter had the highest $\mathrm{O}: \mathrm{C}$ ratio but compared to the less oxidized SVOOA, it had lower average volatility and higher volatility compared to LVOOA. These

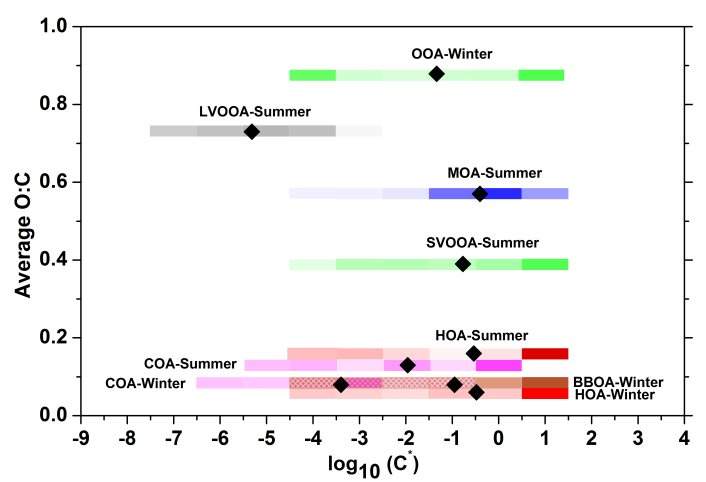

Figure 8. 2D-VBS representation of the PMF factors for the summer and winter campaigns. With the red color of the bars we represent the HOA factors, with the pink color the COA factors, the green the SVOOA and OOA, the blue is for the MOA factor, the brown for the BBOA factor and the black for the LVOOA factor. The darker shading of the colored bars denotes a larger mass fraction for a given $C^{*}$ bin. The diamond represents the average $\log _{10}\left(C^{*}\right)$ value for a given PMF factor.

results indicate that there was not a direct link between the average volatility and the bulk average $\mathrm{O}: \mathrm{C}$ for these $\mathrm{OA}$ components. This is actually the reason for the introduction of the 2D-VBS: the second dimension is needed to capture at least some of the chemical complexity of the multitude of organic compounds in atmospheric particulate matter.

The broad spectrum of volatilities and extent of oxidation are not surprising. Donahue et al. (2012) extrapolated from the few available ambient measurements to provide rough estimates of the factor locations on the 2D-VBS. Superimposition of our factors and those estimated by Donahue et al. (2012) (Fig. S4) indicates that the factor locations agree surprisingly well. This is quite encouraging both for our results and our current understanding of the evolution of atmospheric OA.

\section{Conclusions}

Two month-long field campaigns were conducted at an urban background sampling site, SIRTA in Paris, France as part of the collaborative project MEGAPOLI. The particulate matter mass concentration was surprisingly low during summer in Paris, with a campaign average $\mathrm{PM}_{1}$ OA for SIRTA of only $0.83 \mu \mathrm{g} \mathrm{m}^{-3}$, while during winter it was characterized by higher fine $\mathrm{PM}$ concentrations, with an average $\mathrm{PM}_{1} \mathrm{OA}$ concentration of $3.1 \mathrm{\mu g} \mathrm{m}^{-3}$.

The volatility distributions of PMF factors derived during both campaigns were estimated. Five factors were determined for the summer data set. Hydrocarbon-like OA (HOA), cooking OA (COA), marine OA (MOA) and two Secondary OA (SOA) factors were also identified: semivolatile oxygenated OA (SV-OOA) and low-volatility oxygenated OA (LV-OOA). The PMF analysis for the winter 
campaign determined four factors. The HOA and COA factors were again identified. There was also a single secondary OA factor that was termed oxygenated OA (OOA). The final factor observed was biomass burning OA (BBOA).

The HOA factors for both campaigns had similar volatility distributions with half material in the $10 \mu \mathrm{g} \mathrm{m}^{-3}$ bin. Both factors contained also LVOCs and ELVOCs with a total contribution of around $40 \%$ to the HOA mass. This similarity was consistent with the corresponding mass spectra derived by the PMF analysis.

The summer COA was significantly more volatile than the winter COA. The weighted-average $\mathrm{COA} C^{*}$ during the summer was more than an order of magnitude higher than that in the winter. The winter COA did not contain any semi-volatile organic components (SVOCs) whereas $37 \%$ of the summer COA was semi-volatile. LVOCs were significant components of the COA, representing $37 \%$ of the COA in the summer and $63 \%$ in the winter. These differences in volatility were consistent with the differences in AMS spectra and could be due to different seasonal cooking habits. Also, imperfect separation of the OA components by PMF cannot be excluded.

The LV-OOA factor detected in the summer had the lowest volatility of all the derived factors. There was no sign of LV-OOA evaporation until the TD temperature reached $150^{\circ} \mathrm{C}$. The LV-OOA factor consisted nearly exclusively of ELVOCs (97\%). Roughly half of the SV-OOA mass consisted of SVOCs while the rest was mainly LVOCs (42\%). The OOA factor determined in the winter had a volatility distribution containing SVOCs (45\%), ELVOCs (30\%) and LVOCs $(25 \%)$.

The marine OA (MOA) factor, only detected during the summer campaign, was relatively volatile with an average $C^{*}$ of approximately $0.4 \mu \mathrm{g} \mathrm{m}^{-3}$. The MOA factor consisted mainly of SVOCs $(61 \%)$ and LVOCs $(36 \%)$.

The BBOA factor was present in winter with an average ambient concentration of $0.6 \mu \mathrm{g} \mathrm{m}^{-3}$. Half of the BBOA consisted of SVOCs and the other half of extremely low-volatile and low-volatile organic components. The BBOA was less volatile than the HOA factors but more volatile than COA and OOA.

Finally, combining the $\mathrm{O}: \mathrm{C}$ ratio and volatility distributions of the various factors, we integrated our results into the 2D-VBS synthesizing the corresponding OA findings. The factor locations agreed well with the location of factors proposed by Donahue et al. (2012). The HOA, BBOA, and COA factors had all relatively low $\mathrm{O}: \mathrm{C}$ but their average volatilities were different by orders of magnitude. The MOA for summer and secondary OA factors for both seasons had much higher $\mathrm{O}: \mathrm{C}$ with a wide variety of volatilities, where MOA had the highest one and LV-OOA had the lowest one. The results suggest that the average $\mathrm{O}: \mathrm{C}$ of each factor was not directly linked to its average volatility, underlining the importance of measuring both properties, and that all factors include compounds with a wide range of volatilities.
The estimated volatility distributions by the use of just TD measurements are characterized by considerable uncertainties (Karnezi et al., 2014). However, the relative volatilities of the various factors discussed above should be more robust. The absolute volatility distributions do depend on the assumed enthalpy of vaporization and accommodation coefficient (parameterization of mass transfer resistances). They also depend on the assumptions of similar size distributions and external mixing of the OA components corresponding to each factor.

\section{The Supplement related to this article is available online at doi:10.5194/acp-16-2013-2016-supplement.}

Acknowledgements. This research was supported by the FP7 project MEGAPOLI, the FP7 IDEAS project ATMOPACS, and the ESF-NRSF ARISTEIA grant ROMANDE. Lea Hildebrandt was supported by a Graduate Research Fellowship from the United States National Science Foundation.

Edited by: M. Beekmann

\section{References}

An, W. J., Pathak, R. K., Lee, B.-H., and Pandis, S. N.: Aerosol volatility measurement using an improved thermodenuder: Application to secondary organic aerosol, J. Aerosol Sci., 38, 305314, doi:10.1016/j.jaerosci.2006.12.002, 2007.

Baklanov, A., Lawrence, M. G., and Pandis, S. N.: Description of work document for the European Collaborative Project "Megacities: Emissions, urban, regional and Global Atmospheric POLlution and climate effects, and Integrated tools for assessment and mitigation" (MEGAPOLI) for the Seventh Framework Programme of the European Commission, available at: http://megapoli.info (last access: 1 February 2016), 2008.

Beekmann, M., Prévôt, A. S. H., Drewnick, F., Sciare, J., Pandis, S. N., Denier van der Gon, H. A. C., Crippa, M., Freutel, F., Poulain, L., Ghersi, V., Rodriguez, E., Beirle, S., Zotter, P., von der Weiden-Reinmüller, S.-L., Bressi, M., Fountoukis, C., Petetin, H., Szidat, S., Schneider, J., Rosso, A., El Haddad, I., Megaritis, A., Zhang, Q. J., Michoud, V., Slowik, J. G., Moukhtar, S., Kolmonen, P., Stohl, A., Eckhardt, S., Borbon, A., Gros, V., Marchand, N., Jaffrezo, J. L., Schwarzenboeck, A., Colomb, A., Wiedensohler, A., Borrmann, S., Lawrence, M., Baklanov, A., and Baltensperger, U.: In situ, satellite measurement and model evidence on the dominant regional contribution to fine particulate matter levels in the Paris megacity, Atmos. Chem. Phys., 15, 9577-9591, doi:10.5194/acp-15-9577-2015, 2015.

Burtscher, H., Baltensperger, U., Bukowiecki, N., Cohn, P., Hüglin, C., Mohr, M., Matter, U., Nyeki, S., Schmatloch, V., and Streit, N.: Separation of volatile and non-volatile aerosol fractions by thermodesorption: instrumental development and applications, J. Aerosol Sci., 32, 427-442, 2001. 
Caiazzo, F., Ashok, A., Waitz, I. A., Yim, S. H. L., and Barrett, S. R. H.: Air pollution and early deaths in the United States. Part I: Quantifying the impact of major sectors in 2005, Atmos. Environ., 79, 198-208, doi:10.1016/j.atmosenv.2013.05.081, 2013.

Cappa, C. D. and Jimenez, J. L.: Quantitative estimates of the volatility of ambient organic aerosol, Atmos. Chem. Phys., 10, 5409-5424, doi:10.5194/acp-10-5409-2010, 2010.

Crippa, M., El Haddad, I., Slowik, J. G., DeCarlo, P. F., Mohr, C., Heringa, M. F., Chirico, R., Marchand, N., Sciare, J., Baltensperger, U., and Prévôt, A. S. H.: Identification of marine and continental aerosol sources in Paris using high resolution aerosol mass spectrometry, J. Geophys. Res.-Atmos., 118, 1950-1963, doi:10.1002/jgrd.50151, 2013a.

Crippa, M., DeCarlo, P. F., Slowik, J. G., Mohr, C., Heringa, M. F., Chirico, R., Poulain, L., Freutel, F., Sciare, J., Cozic, J., Di Marco, C. F., Elsasser, M., Nicolas, J. B., Marchand, N., Abidi, E., Wiedensohler, A., Drewnick, F., Schneider, J., Borrmann, S., Nemitz, E., Zimmermann, R., Jaffrezo, J.-L., Prévôt, A. S. H., and Baltensperger, U.: Wintertime aerosol chemical composition and source apportionment of the organic fraction in the metropolitan area of Paris, Atmos. Chem. Phys., 13, 961-981, doi:10.5194/acp-13-961-2013, 2013 b.

DeCarlo, P. F., Kimmel, J. R., Trimborn, A., Northway, M. J., Jayne, J. T., Aiken, A. C., Gonin, M., Fuhrer, K., Horvath, T., Docherty, K. S., Worsnop, D. R., and Jimenez, J. L.: Field-deployable, high-resolution, time-of-flight aerosol mass spectrometer, Anal. Chem., 78, 8281-8289, doi:10.1021/ac061249n, 2006.

Donahue, N. M., Robinson, A. L., Stanier, C. O., and Pandis, S. N.: Coupled partitioning, dilution, and chemical aging of semivolatile organics, Environ. Sci. Technol., 40, 2635-2643, doi:10.1021/es052297c, 2006.

Donahue, N. M., Kroll, J. H., Pandis, S. N., and Robinson, A. L.: A two-dimensional volatility basis set - Part 2: Diagnostics of organic-aerosol evolution, Atmos. Chem. Phys., 12, 615-634, doi:10.5194/acp-12-615-2012, 2012.

Haeffelin, M., Barthès, L., Bock, O., Boitel, C., Bony, S., Bouniol, D., Chepfer, H., Chiriaco, M., Cuesta, J., Delanoë, J., Drobinski, P., Dufresne, J.-L., Flamant, C., Grall, M., Hodzic, A., Hourdin, F., Lapouge, F., Lemaître, Y., Mathieu, A., Morille, Y., Naud, C., Noël, V., O'Hirok, W., Pelon, J., Pietras, C., Protat, A., Romand, B., Scialom, G., and Vautard, R.: SIRTA, a ground-based atmospheric observatory for cloud and aerosol research, Ann. Geophys., 23, 253-275, doi:10.5194/angeo-23-253-2005, 2005.

Huffman, J. A., Docherty, K. S., Aiken, A. C., Cubison, M. J., U1brich, I. M., DeCarlo, P. F., Sueper, D., Jayne, J. T., Worsnop, D. R., Ziemann, P. J., and Jimenez, J. L.: Chemically-resolved aerosol volatility measurements from two megacity field studies, Atmos. Chem. Phys., 9, 7161-7182, doi:10.5194/acp-9-71612009, 2009.

IPCC: Climate Change: The Physical Science Basis - Contribution of Working Group I to the Fifth Assessment Report of the Intergovernmental Panel on Climate Change, edited by: Stocker, T. F., Qin, D., Plattner, G. K., Tignor, M., Allen, S. K., Boschung, J., Nauels, A., Xia, Y., Bex, V., and Midgley, P. M., Cambridge University Press, Cambridge, United Kingdom and New York, NY, USA, 1535 pp., 2013.

Kalberer, M., Paulsen, D., Sax, M., Steinbacher, M., Dommen, J., Prevot, A. S. H., Fisseha, R., Weingartner, E., Frankevich, V., Zenobi, R., and Baltensperger, U.: Identification of polymers as major components of atmospheric organic aerosols, Science, 303, 1659-1662, 2004.

Karnezi, E., Riipinen, I., and Pandis, S. N.: Measuring the atmospheric organic aerosol volatility distribution: a theoretical analysis, Atmos. Meas. Tech., 7, 2953-2965, doi:10.5194/amt7-2953-2014, 2014.

Kostenidou, E., Lee, B. H., Engelhart, G. J., Pierce, J. R., and Pandis, S. N.: Mass spectra deconvolution of low, medium and high volatility biogenic secondary organic aerosol, Environ. Sci. Technol., 43, 4884-4889, 2009.

Lanz, V. A., Alfarra, M. R., Baltensperger, U., Buchmann, B., Hueglin, C., and Prévôt, A. S. H.: Source apportionment of submicron organic aerosols at an urban site by factor analytical modelling of aerosol mass spectra, Atmos. Chem. Phys., 7, 15031522, doi:10.5194/acp-7-1503-2007, 2007.

Lee, B. H., Kostenidou, E., Hildebrandt, L., Riipinen, I., Engelhart, G. J., Mohr, C., DeCarlo, P. F., Mihalopoulos, N., Prevot, A. S. H., Baltensperger, U., and Pandis, S. N.: Measurement of the ambient organic aerosol volatility distribution: application during the Finokalia Aerosol Measurement Experiment (FAME2008), Atmos. Chem. Phys., 10, 12149-12160, doi:10.5194/acp10-12149-2010, 2010.

May, A. A., Levin, E. J. T., Hennigan, C. J., Riipinen, I., Lee, T., Collett, J. L., Jr., Jimenez, J. L., Kreidenweis, S. M., and Robinson, A. L.: Gas-particle partitioning of primary organic aerosol emissions: 3. Biomass burning, J. Geophys. Res.-Atmos., 118, 11327-11338, doi:10.1002/jgrd.50828, 2013.

Murphy, B. N., Donahue, N. M., Robinson, A. L., and Pandis, S. N.: A naming convention for atmospheric organic aerosol, Atmos. Chem. Phys., 14, 5825-5839, doi:10.5194/acp-14-58252014, 2014.

Pope, C. A., III, Ezzati, M., and Dockery, D. W.: Fine-particulate air pollution and life expectancy in the United States, New England Journal of Medicine, 360, 376-386, 2009.

Riipinen, I., Pierce, J. R., Donahue, N. M., and Pandis, S. N.: Equilibration time scales of organic aerosol inside thermodenuders: Evaporation kinetics versus thermodynamics, Atmos. Environ., 44, 597-607, doi:10.1016/j.atmosenv.2009.11.022, 2010.

Saleh, R., Donahue, N. M., and Robinson, A. L.: Time scales for gas-particle partitioning equilibration of secondary organic aerosol formed from alpha-pinene ozonolysis, Environ. Sci. Technol., 47, 5588-5594, doi:10.1021/es400078d, 2013.

Wehner, B., Philippin, S., and Wiedensohler, A.: Design and calibration of a thermodenuder with an improved heating unit to measure the size-dependent volatile fraction of aerosol particles, J. Aerosol Sci., 33, 1087-1093, 2002.

Wehner, B., Philippin, S., Wiedensohler, A., Scheer, V., and Vogt, R.: Variability of non-volatile fractions of atmospheric aerosol particles with traffic influence, Atmos. Environ., 38, 6081-6090, 2004.

Ulbrich, I. M., Canagaratna, M. R., Zhang, Q., Worsnop, D. R., and Jimenez, J. L.: Interpretation of organic components from Positive Matrix Factorization of aerosol mass spectrometric data, Atmos. Chem. Phys., 9, 2891-2918, doi:10.5194/acp-9-2891-2009, 2009.

Zhang, Q., Jimenez, J. L., Canagaratna, M. R., Allan, J. D., Coe, H., Ulbrich, I., Alfarra, M. R., Takami, A., Middlebrook, A. M., Sun, Y. L., Dzepina, K., Dunlea, E., Docherty, K., DeCarlo, P. F., Salcedo, D., Onasch, T., Jayne, J. T., Miyoshi, 
T., Shimono, A., Hatakeyama, S., Takegawa, N., Kondo, Y., Schneider, J., Drewnick, F., Borrmann, S., Weimer, S., Demerjian, K., Williams, P., Bower, K., Bahreini, R., Cottrell, L., Griffin, R. J., Rautiainen, J., Sun, J. Y., Zhang, Y. M., and Worsnop, D. R.: Ubiquity and dominance of oxygenated species in organic aerosols in anthropogenically-influenced Northern Hemisphere midlatitudes, Geophys. Res. Lett., 34, L13801, doi:10.1029/2007GL029979, 2007.
Zhang, Q., Jimenez, J. L., Canagaratna, M. R., Ulbrich, I. M., Ng, S. N., Worsnop, D. R., and Sun, Y.: Understanding atmospheric organic aerosols via factor analysis of aerosol mass spectrometry: a review, Anal. Bioanal. Chem., 401, 3045-3067, 2011. 